\title{
The Place of History in Health Care Service Delivery: How Useful to Nigeria's Health Care System
}

\author{
Labbo Abdullahi, Ph.D \\ Department of History, Usmanu Danfodiyo University, Sokoto
}

Listen to your patient. He is telling you the diagnosis (Sir William Osler, 1848-1919) emphasizes the importance of taking good history in clinical service delivery.

\section{Abstract}

History is a collection of records of the past happenings and experiences. Historians ask when, where and what happened in the past and historical records answer such questions satisfactorily. A number of epidemic and endemic diseases as well as illnesses and treatments occurred in the past upon which records are kept in various medical institutions and centres for historical researches. Health care practitioners ask such questions as when, where and how a disease or illness started and what type of treatments have been given over time. Historical records and oral interactions with patients answer such questions and throw light for further health care services. History also, reviews key issues in health care developments, provide insights into the challenges confronting health care delivery, bring out past mistakes including medical errors and make a compelling case for change. This article adopted qualitative approach and analyzed the extent to which history plays vital roles in health care service delivery. It is discovered that historical records are essential assets in ensuring that health care institutions and services are run effectively and efficiently. The records support not only clinical decisionmaking, but also health care policy-making in general and provide the reasons for the failures and successes of the past policies and services. Finally, the article shows how useful can the use of history be, in Nigeria's health care system.

Keywords: History, Disease, Illness and Health care Service Delivery.

DOI: $10.7176 / \mathrm{HRL} / 51-01$

Publication date: February $29^{\text {th }} 2020$

\section{Introduction}

Many people do not appreciate the importance of history and its usefulness in human endeavours including health care system. Similarly, quite a number of people seem to misconceive history as mere account of empires, kingdoms, chiefdoms and warfare that has no any role to play in the development of science and technologies. However, understanding history of any endeavour is central for its comprehensiveness. History plays a vital role in the development of every society in the world. Related to this, Livy puts that, history is the best medicine for a sick mind; for in history you have a record of infinite variety of human experience plainly set out for all to see; and in that record you can find yourself and your country both examples and warnings: fine things to take as models, base things, rotten through and through, to avoid (Livy, 2002). Health on the other hand is regarded all over the world as a treasure, and it is believed that investing in health produces positive outcomes in human capital that have long term impact in the overall socio-economic development of every society (Mwabu, 1998: 2). Illness and disease prevent effective performance of societal roles, and thus, every society has a deep interest in the control of disease and illness for the maintenance of good health.

This article delves on how the past preserved by written and oral history enhances and facilitates health care service delivery through patient-physicians' interactions and educating health care personnel as well as other public stakeholders on the past experiences. The major targets of the discourse are the roles of history and historians in clinical services, family health history as an important tool in clinical services as well as the role of history in the development of health care facilities and promotion of public health. The article concludes by analyzing the importance of an accurate and proper documentation of history taking in health care institutions and its integration in the curriculum of health care students.

\section{Contextualizing Health care Service Delivery and History}

Although it may appear too elementary at this juncture to clarify the concepts of health care service delivery and history, it is imperative to contextual the concepts within the discourse of this article. The concept of health refers to the state of complete physical, mental, and social well-being and not merely the absence of disease or infirmity (WHO, 1946); while health service refers to any service aimed at contributing to improved health or to diagnosis and treatment of patients (WHO, 1998). Health care system consists of all organizations, people and actions with the primary intent to restore, promote and maintain health and one of its major components is service delivery. Health service delivery involves all efforts that could promote health whether preventive or control activities. The efforts are so important to human functioning and therefore, every society deserves good health service delivery that is effective, safe, accessible, qualitative and available wherever and whenever needed 
(Amza and Razum, 2014: 223-4). History on the other hand is defined as the record of what has happened in the past, of anything that has ever happened in the past, however long ago or recently (Clark: 1967: 1). Yandaki (2015: 208) indicates that all human societies had had the tendency to preserve, learn or inquire various forms of history about themselves and transmit same to their on-coming generation.

Moreover, history aims at giving thorough ground information about the past in order to explain not only the past but also prevailing problems and understand how the present situation emerged from the past. However, for the purpose of this paper, history is the established information of the past happenings recorded in writing or preserved orally and also a process of enquiring, recording, establishing and reconstructing of such information about the state of peoples' health and health care service delivery. It is imperative to note that the work of historian as according to Leopold Vom Rankes' tradition is "to show as it really was" although, Carr lampooned the tradition in his book What is History (1984), the tradition is the perfect work of history in its relation to clinical aspect of health care services. The interpretation of the information to the final conclusion is the work of physicians who possessed the scientific knowledge of diseases, illnesses and their symptoms over the time. However, the evolutionary process of acquiring such experiences over the time is also historical development that can be recorded for perusal by the on-coming generations of health care providers in training.

\section{History, Historian and Health care Service Delivery}

Generally, Carr (1984: 19) indicates that, the function of the historian is to master and understand the past as the key to the understanding of the present. However, the concern of an historian in health care delivery is to use different strategies to produce evidences about the state of health, disease and medical practices in the past. He produces relevant information for public health stakeholders through the following ways: studies of specific sources of morbidity using historical approach to scrutinize: the outbreaks of past epidemics (smallpox, cholera, Lassa fever and influenza); persistent sources of endemic diseases (malaria and tuberculosis) and patterns of chronic and genetic diseases (noninsulin independent diabetes, mellitus, sickle cell and obesity) (Bivins, 2007: 61). Such studies promote a deeper understanding of the existing factors of morbidity and mortality as well as the impact of earlier attempts to address them. An historian studies institutions and entities that affect health through examination of the role of global trading companies, militaries, missionaries in the spread of diseases; for instance, globalization of cholera, flu (influenza), tuberculosis, syphilis, HIV/AIDS and yaws (Dangamuzza, 2012) and the impact of the WHO, national governments, private charities in the eradication efforts of same global diseases. These studies on the other hand render visible; the diversity of actors and range of interests involved in global promotion of public health.

A social historian of medicine compares historical and contemporary responses to global health challenges, makes comparative analysis of the past and present responses to morbidity and examines the relative efficacy of past and current public health strategies against epidemic and endemic diseases. Such studies illuminate continuities and changes in public and political attitudes towards health. Finally, the work of an historian which includes some of the major themes in social history of medicine are: the study and evaluation of cross-cultural exchanges of knowledge and practice studies by comparing transmission of medical knowledge across the globe and particularly the introduction of Western medical culture in non-western societies, assessing medical 'cultural clashes' between Western and indigenous medical practices (modern and traditional medicines). Such types of studies illustrate fundamental characteristics of different medical systems, effective and ineffective practices and strategies in health care service delivery (Bivins, 2007: 63-64). The following sections are on the detailed exposition on the usefulness of history and an historian in various aspects of health care service delivery.

\section{History and Clinical Service Delivery}

The role of history and an historian in clinical aspect of health care services cannot be over-emphasized. An historian here does not only mean a professional and trained historian but also a patient who is knowledgeable about his or her medical history, oral or documented. History and an historian account for many of the problems associated with current human health conditions. According to Karen (2013), to understand today's health problems, look at evolutional past. She appreciates the relevance of understanding current health problems through the knowledge of the past. This signifies that humans need to keep their health associated evolutionary history in mind and written in order to deal with present the health problems in a productive way. Karen then, adds that, we need to understand our evolutional history in order to understand why we have some of the maladies that we have.

The whole idea behind the two statements by Karen indicates that hindsight provides the knowledge of the present as well as foresight for clinical service delivery. Perhaps, this was the reason why the father of modern medicine, Osler emphasizes on the importance of taking a good history in clinical service delivery and he maintained that, diagnosis is revealed in the patients' history (Skelton, 2008: 33). Osler is popular in the medical world with his saying: listen to your patients they are telling you the diagnosis. However, it is important to stress that Osler did not mean it literally. Patients do not offer up esoteric and complete medical diagnoses on a silver 
platter. They only provide clues in plain language to their physicians who are to listen to carefully in order to make the correct diagnosis. Osler was a physician and historian and his saying became a much quoted aphorism. His greatest contribution to health care system was his insistence that medical students should learn from talking to patients in which he emphasizes the importance of taking a good history. Therefore, the inference that can be drawn from his saying is that listening to patients provides what is wrong with them to physicians and is the most important tool for solving the patients' medical problems.

Clinically, the basis of history is good communication between a physician and a patient since the information by the patient support clinical decision making by his physician. A good history is one which reveals patients' ideas, experiences and accompanying diagnosis. More often than not, history alone cannot reveal a diagnosis but it is all that is required, to make a diagnosis. However, in some instance, a detailed history can be self-explanatory and a diagnosis of itself. A good example is in women with history of childhood abuse. It is confirmed that such women exhibited increased pituitary adrenal (hypophysis) and autonomic responses to stress in adulthood compared to controls (Singer and Ryff, 2001: 31). Likewise, a history of traumatic stress is one of the most reliable factors predicting thyrotoxicosis (medical state caused by thyroid gland) (Singer and Ryff, 2001: 37).

History often reveals diagnoses more than the diagnostic equipment in Nigeria's clinical services. For instance, looking at the rural population in Nigeria that has been accounting between 80 percent in 1978 and 53 percent in 2014 of the country's population; where there has been no diagnostic equipment (Onokerhoraye, 1978: 29; Cornelius, nd: and World Bank, 2015), quite a number of history-based diagnoses were made. Conclusion can therefore, be made that the use of history although with high risk has been accounting between 80 and 50 percent of the diagnoses in Nigeria's health care service delivery from 1970s to 2014.

According to Salisu (2016), the content of the history required in primary care consultations depends on the presenting symptoms, patients' experiences and the past medical, psychological and social history. However, good physicians are those with conventional techniques of following the general framework for history taking which begins with presenting complaints, enquiry into the history of the presented patient and complaints; including investigations, treatment and referrals; family health history (parents, siblings and children) and social history (smoking, alcoholism, womanization, drug addiction, accommodation, marital status and hobbies). Salisu concluded that the system of history taking is the culture of modern health care service providers all over the world and Nigeria inclusive.

Evidently, whenever a patient appears before a Nigerian physician the first thing is always inquiry into the history of the sickness especially when and how it started. A file is usually opened while recording down the received historical information. Thereafter history taking, good physicians usually reflect back to history for identification of whether similar symptoms appeared on some recovered patients and what type of treatments were given to them. In relation to this, Yandaki (2015: 2) indicates that history in its original etymology is a Greek word meaning "a leaning or knowing by inquiry". Therefore, all medical practitioners have the tendency to learn or know the origins and nature of diseases and sicknesses through inquiry into the past. The information received serves as primary diagnosis and pathfinder for proper scientific diagnosis and eventually treatment. It is also for the physicians' use; the patients' records are kept in various record offices of Nigeria's medical institutions.

A number of clinical errors occur in health care service delivery even in the developed world, for instance, about 180,000 died each year in USA because of medical errors (Kamorudeen, 2013: 8). But the errors are rampant in developing countries like Nigeria. Medical errors lead to quite a number of premature deaths and incapacitation in Nigeria. The use of history in this regard is to learn from the past errors on how and why the errors and what were the consequences. That is why Livy says ... and in that record you can find yourself and your country both examples and warnings; fine things to take as models and things rotten through and through to avoid. In the same vein, the point of Churchill is instructive in this regards: "The longer you look back, the further you can look forward. For those who fail to read history are destined to suffer the repetition of its mistakes (Winston Churchill).

Therefore, history helps to identify where service delivery has been accurate or otherwise in the treatment of illnesses. It is obvious that, Nigerian health sector is faced by challenges of funding, poor health facilities, prevalence of quack health care providers and unethical clinical drugs' trials (Kamorudeen, 2013: 9). These challenges are capable of influencing clinical errors leading to deaths. For instance, Polgreen (2009) reported that between November, 2008 and February, 2009 at least 84 children died after taking a medicine for teething pain, in Lagos. Another instance was the case of clinical trial of Trovan Antibiotic by Pfizer Pharmaceutical Company in Kano, Nigeria; during 1996 meningitis epidemic. Among the two hundred (200) stricken children involved in the trial study, eleven died, while other suffered from meningitis related complications such as deafness and blindness (Kamorudeen, 2013: 10). 


\section{The Factor of Family Health History in Clinical Service Delivery}

Family health history is very central in health care service delivery all over the world and Nigeria inclusive. This is because scientifically many diseases are thought to be caused by a combination of genes. Although, if a person has a disease does not mean his children and grand-children will necessarily get it, they have a greater chance of developing the disease than someone without a similar family history (Salisu, 2016). Health problem that may run in families included Alzheimer's disease or dementia, arthritis, asthma, blood clots, cancer, depression, diabetes, heart disease, high cholesterol, high blood pressure, pregnancy losses and birth defect as well as stroke (Salisu, 2016). Similarly, family health history shows that some diseases are clearly heritable. This means that the diseases come from a mutation or harmful change, in a gene inherited from one or both parents. Examples of such diseases included Huntington's disease, cystic, fibrosis and muscular dystrophy. Therefore, family health history helped medical researchers in identification and confirmation, and continue to identify and confirm diseases that are heritable (Salisu, 2016).

\section{History and Health care Facilities}

Another aspect of the relevance of history is about the development of health care facilities in the country. Taking Nigeria as an example here, considering the fact that, conventional health care system has been in the country for decades since it was introduced by missionaries (Schram, 1971: 103); one cannot help but wonder why the health situation in the country is still in such a poor state. How did it all happen? How did Nigerians get into the present situation? What can Nigeria's system learn from past experience? What strategies, if any have worked well in the provision of health care facilities? Which ones did not work well and why? What are the persisting weaknesses in the Nigeria's health care system? What will need to be done or changed to achieve sustainable, equitable, effective and efficient health care facilities in Nigeria? These questions and many more constitute a serious challenge to Nigerian Government and they can be adequately addressed by historical studies. Therefore, history is the review of the progress or otherwise of what has been done in the development of Nigeria' health care facilities and every nation or society in the world. It provides insights and foresight into the challenges confronting the state of health and health care system of every society.

\section{History and Promotion of Public Health}

With regards to promotion of public health; history brings to the fore, the role of physical, social, economic and environmental factors in the outbreaks and spread of diseases as well as the roles of institutions in the control of such diseases. The whole idea of prevention of diseases was developed upon historical knowledge. For in order to prevent the recurrence of the outbreaks and mortality of diseases; health professionals always refer to the history of such outbreaks, mortality rates and control measures. They also follow the same methods while trying to control the maladies of present situation (Singer and Ryff, 2001: 92).

Public health providers can develop strategies for promotion of health using history as a health 'laboratory' in comparing historical and contemporary responses to health problems; through assessing the successes and failures of different health interventions and strategies. Taking Nigeria for instance, the country has been well known with such infectious diseases as smallpox, measles, tuberculosis, cholera, yaws, yellow fever and meningitis as well as sexually transmitted diseases. Some of the diseases, for instance; tuberculosis, cholera and syphilis were believed to be imported into the country (Bivins, 2007: 11-14 and Dangamuzza, 2012). However, some of the imported diseases were controlled in the developed world where they were believed to be originated; through vaccination, quarantine and environmental sanitation (Bivins, 2007: 24). Although, the same strategies have been in application in Nigeria's promotion of public health, such diseases as cholera and TB are still prevalent in the country.

The usefulness of history in this regards is addressing what are the problems by comparing historical and contemporary responses to diseases and strategies of promotion public health within and outside Nigeria. This helps in the assessment of long-term efficacy of different strategies of historical and contemporary strategies. The use of past in controlling the present health situation could be found in the use of history of promoting public health even in the developed nations. For instance, when United Kingdom was much concerned about the control of tuberculosis between 1948 and 1968; the then minister of health decided to use the method found in history (Bivins, 2007: 30-34). He was reported to have said:

We have spent an enormous amount of energy and money in attempting to rid this region of $\mathrm{TB}$ and it is being imported into the country without our being able to do anything about it....why didn't the UK follow the examples of Canada, Australia and the United States, and establish a medical border against the 'immigrant menace'? (Bivins, 2007: 40).

The situation in UK with regards to TB infection by the time was so serious for after its rates fell drastically since 19th century, the infection began to rise again in urban areas with the coming of large immigrants. This brought public fears as it threatened the public health. Therefore, the UK Ministry of Health adopted the 
strategies of Canada, Australia and USA by addressing the menace at the UK's borders (Bivins, 2007: 35).

Smallpox and cholera are examples of infectious diseases that were controlled in the past in the developed nations. Although, the former was never experienced in Nigeria since the world was declared free of it in 1980, the latter persists to cause sporadic high mortality in the country. Smallpox was controlled through effective vaccine; global and national actions; voluntary and rather than compulsory actions, but carrot (for example vaccination was made necessary to gain passport or entry to other nations) and stick (for example military-run mass vaccination activities during epidemics) approaches as well as health education (Bivins, 2007: 51-53). Nigeria had a history of smallpox outbreaks with high mortalities up to the 1970s Nigerian Governments' eradication campaign in partnership with the United States Action for International Development brought about an end to the disease (WJHCB/NA/MH/012). Cholera outbreaks were one of the first governmentally and institutionally recognized cases of 'global disease'. From $19^{\text {th }}$ and on-ward to the $20^{\text {th }}$ centuries six classical cholera pandemics occurred in the world (Bivins, 2007: 57). The first experience of the epidemic in Nigeria was in 1970s. This was the period after the disease was almost controlled in the developed world (WJHCB/SOKPROF/BCD/10/).

The past techniques employed to halt the spread of cholera disease were quarantine, introduction of pure water supplies, sanitation, support for improved environmental and agricultural conditions and education about food and toilet hygiene for all (Bivins, 2007: 58). History identifies which of those methods were effective and worked and which were ineffective and did not work in the past. This was for the purpose of best strategies in the present and future cholera control and prevention in Nigeria. In other words, this means building control and prevention approaches on the explored historical experiments.

\section{Conclusion}

In the final analysis, the paper studied the relevance of history in health care service delivery and showed how it can be useful in Nigeria's health care system. It is clear that the functions of history and a historian are very fundamental in the country's health care service as elsewhere. Obviously, most of the Nigerian health problems have been the same throughout history. Few health situations arise today for which there is no historical precedent. Therefore, it is imperative for people working in Nigeria's health care system to use history of health problems, solutions, and co-factors as they address contemporary Nigeria's health challenges. The need for rigorous research on the social history of medicine and the integration of its knowledge in the curriculum of Nigerian health care students is imperative. In this regards, William Whewells' 1840 notion of consilience is important. The notion reads "jumping together" of knowledge by the linkage of facts and fact-based on theory across disciplines to create a common groundwork of explanation (Wilson, 1998:8). On the expatiation of the notion, Wilson (1998) says "a unified system of knowledge provides a clear map of what is known and it frames the most productive questions for future enquiry and represents more distant horizons for promoting health and well-beings.

It is equally important to note that, today there is a field of study known as medical history and or social history of medicine. According to Burnham in his What is Medical History (2005), the field is identified with the following targets: study of health care providers in all times and places from conjures to technical specialists; patients from all ages and cultures; diseases from possession by demons to infections; discovery and the communication of ideas, great and trivial, flawed and brilliant. Scholars like Sigerist (1946); Swear (1992) and Rosenberg (2007) coined the field or sub-discipline as Social History of Medicine.

\section{References}

Alhasan Dangamuzza (21/11/12); a former No.3 Medical Field Unit Officer, Oral Interview at his Residence

Amzat J. and Razum O. (2014). "Medical Pluralism: Traditional and Modern Health Care" Medical Sociology in Africa, Springer International Publishing Switzerland

Bivins R. (2007). "Global Health in Historical Perspective: The Uses of History". A Paper prepared as part of an education project of the Global Health Education Consortium at Cardiff University

Brandt A.M. (1991). "Emerging Themes in the History of Medicine", Milbank Quarterly, Vol. 62, No. 2

Burnham J.C. (2005). What is Medical History? Polity Press, Cambridge

Clark G.K. (1967). The Critical Historian, Heinemann, London

Cornelius C.A. "Population Growth and the Dilemma of Rural Life and Economy in Nigeria" undated paper available www.ajol.info/index.php/ujah/.../54021, retrieved on 21/02/2016

Tanimun Salisu (MBBS) (15/02/2016), Specialist Hospital Sokoto, Oral Interview in his office

Health Reform Foundation of Nigeria (HERFON) (2007), "Nigeria Health Review", Primary Health care in Nigeria 30 Years after Alma Ata

Kamorudeen A. (2013). "Sins of Omission: An Invitation to Research on Medical Errors in Developing Countries", Kaduna Journal of Sociology (KJS), Vol.1, No.1

Karen R. (2013). Address at the Annual Meeting of the American Association for the Advancement of Science 
(AAAS) on Friday, 15, in Boston

Mwabu G. (1998). "Health Development in Africa", Economic Research Papers Series (38)

Onokerhoraye A.E. (1978), "Planning for Rural Development in Nigeria: A Spatial Approach" Community Development Journal, Vol. 13 No.1

Polgreen L. (2009). "84 Children are Killed by Medicine in Nigeria", the New York available at www.nytimes.com/2009/02/07/world/Africa/07nigeria.hyml>

Rosenberg C. (2007). "Erwin H. Ackerknecht, Social Medicine and the History of Medicine", Bulletin of the History of Medicine, 18

Schram R. (1971). A History of the Nigerian Health Services, Ibadan University Press

Shaw T. (1969). Lectures on Nigerian Prehistory and Archaeology, Ibadan University Press

Sigerist H.E. (1946). Address to Johns Hopkins Medical Club

Singer B.H. and Ryff C.D. (2001). "New Horizons in Health: An Integrative Approach" A Project Prepared by Committee on Future Directions for Behavioural and Social Sciences Research at the National Institutes of Health available at www.napedu/catalog/10002html

Skelton J. (2008). Role Play and Clinical Communications: Learning the Game, Padcliffe Publishing

Wear A. (1992). Medicine in Society: Historical Essays, Cambridge University Press

Wilson E.O. (1998). Consilience: the Unity of Knowledge, (New York: Alfred A. Knopf)

WJHCB/NA/MH/012/VOL.II/SOKPROF/Smallpox Control and Treatment Policy and Instruction, 1961-1967

WJHCB/SOKPROF/BCD/10/Gusau Hospital Extension 1955-1959

World Bank Estimates Base on United Nations, World Urbanization Prospects, Catalog Sources, available at www.data.worldbank.org/indicator/sp.rur.totl.2s?page $=2$

World Health Organization (WHO) (1946). Preamble to the Constitution as Adopted by the International Health Conference, New York, 19-22, June

World Health Organization (WHO) (1998) Regional Office for Europe, WA Glossary of Technical Terms on the Economics and Finance of Health Services available at http://www.euro.who.intl.

Yandaki A.I. (2015). The State in Africa: A Critical Study in Historiography and Political Philosophy, Gaskiya Corporation Limited. Zaria: Nigeria

Titus L.P. (Livy) (2002), The Early History of Rome, Penguin Classics 